\title{
Deprotection of di-O-isopropylidene isocarbonucleosides
}

\author{
María F. Martínez Esperón, María I. Errea, Miriam A. Martins Alho, \\ and Norma B. D’Accorso*
}

CIHIDECAR, Departamento de Química Orgánica, Facultad de Ciencias Exactas y Naturales, Universidad de Buenos Aires. 3er. Piso, Pabellón II, Ciudad Universitaria. CP 1428.

Buenos Aires, Argentina

E-mail:norma@qo.fcen.uba.ar

\section{Dedicated to Professor E. A. Ruveda and Professor R. Rossi}

(received 24 Jul 03; accepted 22 Oct 03; published on the web 30 Oct 03)

\begin{abstract}
Deprotection of 5-glycosyl heterocyclic derivatives of 1,2:3:4-di- $O$-isopropylidene- $\alpha$-D-galacto1,6-hexadialdo-1,5-pyranose allowed isocarbonucleoside analogues to be obtained with enhaced solubility in the aqueous medium used for antiviral assays. Looking for a deprotection method of isopropylidene groups which would not affect the heterocycle, we performed and compared different deprotection techniques using microwave radiation or thermal heating and found that, in most cases, this goal could be achieved, in short times and good yields, when the reactions were microwave-assisted.
\end{abstract}

Keywords: Isocarbonucleosides, microwaves, isopropylidene deprotection

\section{Introduction}

The synthesis of heterocyclic rings linked to a sugar moiety has been of great interest due to their pharmacological activity. ${ }^{1-6}$ We previously reported the synthesis of 5-glycosyl heterocyclic derivatives of 1,2:3:4-di- $O$-isopropylidene- $\alpha$-D-galacto-1,6-hexadialdo-1,5-pyranose. ${ }^{7,8}$ Deprotection of these compounds led to isocarbonucleoside analogues. Thus, their solubility increased in the aqueous medium used for antiviral assays.

Söderberg et al. ${ }^{9}$ reported the microwave-assisted deprotection of 1,2:5:6-di- $O$ isopropylidene- $\alpha$-D-glucofuranose in good yield. Due to the short times involved in the microwave-assisted reactions, the yields of sugars linked to an acid-labile heterocycle could be improved compared to those obtained using traditional thermal conditions.

This paper reports the results obtained by comparing thermal and microwave- assisted

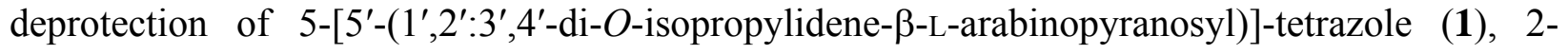


amino-5-[5'-(1',2':3',4'-di- $O$-isopropylidene- $\beta$-L-arabinopyranosyl)]-1,3,4-thiadiazole $\quad$ (2), $\quad 2$ phenyl-5-[5' $-\left(1^{\prime}, 2^{\prime}: 3^{\prime}, 4^{\prime}\right.$-di-O-isopropylidene- $\beta$-L-arabinopyranosyl)]-1,3,4-oxadiazole (3) and 2methyl-5-[5'-(1',2':3',4'-di-O-isopropylidene- $\beta$-L-arabino-pyranosyl)]-1,3,4-oxadiazole (4).

\section{Results and Discussion}

\section{Chemistry}

Compounds 1 and $\mathbf{4}$ were synthesized as previously described but, in the case of compounds 2 and 3, the synthetic pathway was improved respect to our earlier reports. ${ }^{7,8}$

Compound 2 was synthesized by treatment of 1,2:3,4-di- $O$-isopropylidene- $\alpha$-D-galacto-1,6hexadialdo-1,5-pyranose thiosemicarbazone ${ }^{8}$ with ferric chloride in a microwave-assisted solvent-free reaction. Although the product was obtained in similar yield to that reported earlier, the simplicity of the work-up justifies the replacement of the older methodology to obtain this kind of compounds.

The phenyl oxadiazole 3 was obtained from 1,2:3,4-di- $O$-isopropylidene- $\alpha$-D-galacto-1,6hexadialdo-1,5-pyranose benzoylhydrazone (5, which is described in the Experimental Section) using hypervalent iodine (PIDA). This pathway led to compound $\mathbf{3}$ in a shorter time, in higher yield and with an easier work-up than described previously.

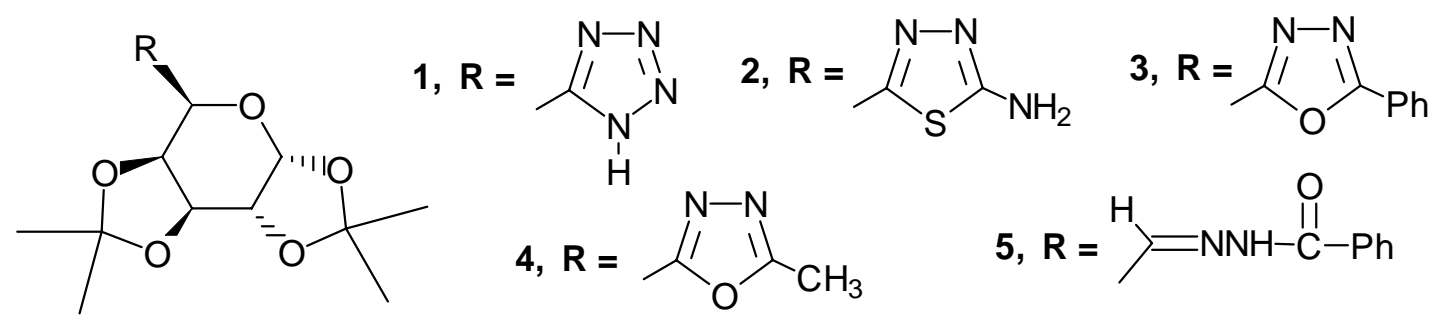

\section{Figure 1}

\section{Thermal and microwave-assisted deprotection}

Performing deprotection reactions either with thermal or microwave heating, the results were closely related to the nature of the heterocyclic ring. Indeed, when thermal treatment was applied, the tetrazole derivative 1 could be deprotected using aqueous acetic acid (10\%) in good yield. However, in the case of the oxadiazoles $\mathbf{3}$ and $\mathbf{4}$, best results were obtained using sulfuric acid $(8 \%)$. On the other hand, the thiadiazole derivative 2 did not resist treatment with hot acidic medium, decomposing.

Applying microwave radiation, as expected, deprotection times were shorter and the product yields were similar or higher. The greatest decrease in reaction time was observed for the deprotection of compound $\mathbf{1}$, in this case the reaction time decreased from $18 \mathrm{~h}$ to 5 ' 30 '. It is 
important to point out that deprotection of compound 2 was only achieved when the reaction was microwave-assisted.

In the case of compound 4, full deprotection of the sugar moiety was achieved in a short time but studying the products obtained by ${ }^{1} \mathrm{H}$ and ${ }^{13} \mathrm{C}$ NMR, opening of the heterocycle occurred. The instability of the oxadiazoles under hydrolytic $\left(\operatorname{acidic}^{10}\right.$ or basic ${ }^{11}$ ) thermal conditions was already known and, unfortunately, cleavage of the heterocycle could not be avoided using microwave radiation. As a matter of fact, when compound 4 was irradiated for only 40 seconds, partial sugar deprotection as well as partial heterocycle hydrolysis was also observed.

On the other hand, since aryl substituted oxadiazoles are less sensitive to hydrolysis than their alkyl analogues, ${ }^{10}$ deprotection of compound $\mathbf{3}$ could be achieved in a short time and in high yield under microwave radiation.

The results are summarized in Table 1.

Table 1

\begin{tabular}{|c|c|c|c|c|c|c|c|}
\hline \multirow[b]{2}{*}{ Comp } & \multicolumn{4}{|c|}{ Thermal Treatment } & \multicolumn{3}{|c|}{ Microwave Irradiation } \\
\hline & Cond. & Time & Temp. & Yield & Cond. & Time & Yield \\
\hline 1 & $I$ & $18 \mathrm{~h}$ & $80^{\circ} \mathrm{C}$ & $86 \%$ & $I$ & $5 ’ 30 \prime$ & $89 \%$ \\
\hline 2 & III & $5 \mathrm{~h}$ & $60^{\circ} \mathrm{C}$ & (a) & $V I$ & $40 ”$ & $42 \%$ \\
\hline \multirow[t]{4}{*}{3} & $I I$ & $6 \mathrm{~h}$ & $80^{\circ} \mathrm{C}$ & n.r & $I$ & 2’20”' & n.r. \\
\hline & $I I I$ & $1 \mathrm{~h}$ & $60^{\circ} \mathrm{C}$ & $93 \%$ & $I V$ & $10 ”$ & (b) \\
\hline & & & & & $V$ & 1 & n.r. \\
\hline & & & & & $V I$ & 1'20”' & $97 \%$ \\
\hline \multirow[t]{2}{*}{4} & III & $10 \mathrm{~h}$ & $60^{\circ} \mathrm{C}$ & (b) & $V I$ & $40 ”$ & (c) \\
\hline & & & & & $V I$ & $1 ’ 20 ”$ & $72 \%(d)$ \\
\hline
\end{tabular}

(a) Decomposition. (b) Partial decomposition. (c) Partial deprotection (d) Ring opening Conditions: I: AcOH (10\%)/ $\mathrm{H}_{2} \mathrm{O}$. II: AcOH (10\%)/Acetone. III: $\mathrm{H}_{2} \mathrm{SO}_{4}(8 \%) /$ Acetone. IV: $\mathrm{H}_{2} \mathrm{SO}_{4}(8 \%) / \mathrm{H}_{2} \mathrm{O}$.

According to the literature, ${ }^{12,13}$ since deprotection of galactose residues releases the carbonyl groups, both pyranose and furanose ( $\alpha$ and $\beta$ ) forms were present in most of the deprotected products. From compounds 1 and 4, although the pyranose forms predominated, smaller proportions of furanose forms ( 7 and $10 \%$, respectively) were also detected. Deprotection of compound 3 gave rise to a complex mixture of four structures with pyranose and furanose ( $\alpha$ and $\beta$ ) forms, whereas the galactose residues arising from compound 2 were only found in the pyranose forms.

Deprotection of compound 1 gave 5-[5'-( $\alpha$-L-arabinopyranosyl)]tetrazole $(6 \mathbf{6 a})$ and 5 -[5'-( $\beta$-Larabinopyranosyl)]tetrazole (6b) as main products, and compound 2 originated 2 -amino-5-[5' $-(\alpha$ L-arabinopyranosyl)]-1,3,4-thiadiazole (7a) and 2-amino-5-[5'-( $\beta$-L-arabinopyranosyl)]-1,3,4thiadiazole (7b). Deprotection of compound 3 yielded 2-phenyl-5-[5'-( $\alpha$-L-arabinopyranosyl)]- 
1,3,4-oxadiazole (8a), 2-phenyl-5-[5'-( $\beta$-L-arabinopyranosyl)]-1,3,4-oxadiazole (8b), 2-phenyl-5[5'-( $\alpha$-L-arabinofuranosyl)]-1,3,4-oxadiazole (8c) and 2-phenyl-5-[5'-( $\beta$-L-arabinofuranosyl)]1,3,4-oxadiazole (8d). Compound 4 produced mainly, $N$-acetyl- $\alpha$-D-galacturonopyranosyl hydrazide (9a) and $N$-acetyl- $\beta$-D-galacturonopyranosyl hydrazide (9b) (Figure 2).

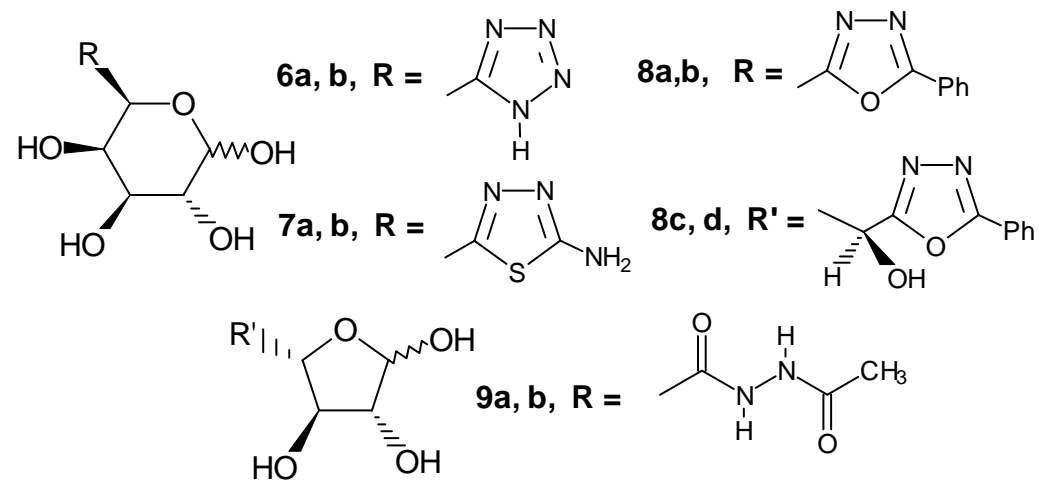

Figure 2

\section{NMR spectroscopy of deprotected compounds}

In spite of the complexity of the ${ }^{1} \mathrm{H}$ NMR spectra of compounds 6, 7 and 9, almost all the signals could be assigned using first order analysis. To assign the signal corresponding to H-3 of the $\alpha$ and $\beta$ structures of compound $\mathbf{6}$, a COSY spectrum was recorded. Results of these assignments are summarized in Table 2.

The ${ }^{13} \mathrm{C}$ NMR spectrum of compound 6 was assigned by HETCOR, and the chemical shifts of compound 6 were used as a model to assign the ${ }^{13} \mathrm{C}$ NMR resonances of $7 \mathbf{a}-\mathbf{9 a}$ and $\mathbf{7 b}-\mathbf{9 b}$ (Table 3). Galactofuranose ${ }^{14}$ was the model compound used to assign the signals of $\mathbf{8 c}$ and $\mathbf{8 d}$ (Table 4).

In summary, carrying out the deprotection reactions under microwave radiation, rates were enhanced while the yields were similar or higher with respect to those obtained under thermal heating. Particulary relevant was the result obtained after the deprotection of 2-amino-5-[5'$\left(1^{\prime}, 2^{\prime}: 3^{\prime}, 4^{\prime}\right.$-di- $O$-isopropylidene- $\beta$-L-arabinopyranosyl)]-1,3,4-thiadiazole since, in this case, the deprotected product could not be obtained without microwave assistance. This methodology offers a rapid and effective deprotective synthetic step when carbohydrates and an acid-labile heterocycle are involved. 
Table 2. ${ }^{1} \mathrm{H}$ NMR data of $\mathbf{6 , 8}, \mathbf{8}$ and $9\left(\mathrm{D}_{2} \mathrm{O}\right): \delta_{\mathrm{H}}[\mathrm{ppm}]$ and coupling constants J $[\mathrm{Hz}]$

\begin{tabular}{|c|c|c|c|c|c|}
\hline Compound & $\mathrm{H}-\mathrm{1}^{\prime}$ & $\mathrm{H}-2^{\prime}$ & $\mathrm{H}-3^{\prime}$ & $\mathrm{H}-4^{\prime}$ & H-5 \\
\hline \multirow{3}{*}{$6 a$} & 4.98 & 3.75 & 4.06 & 4.46 & 5.46 \\
\hline & d & $\mathrm{dd}$ & $\mathrm{dd}$ & $\mathrm{dd}$ & $\mathrm{d}$ \\
\hline & $J_{1^{\prime}, 2}=7.9$ & $J_{2^{\prime}, 3^{\prime}}=10.0$ & $J_{3^{\prime}, 4}^{\prime}=3.6$ & $J_{5^{\prime}, 4^{\prime}}=1.1$ & \\
\hline \multirow{4}{*}{$6 b$} & 5.60 & 4.06 & 4.22 & 4.51 & 5.75 \\
\hline & $\mathrm{d}$ & $\mathrm{dd}$ & $\mathrm{dd}$ & $\mathrm{dd}$ & $\mathrm{d}$ \\
\hline & $J_{1^{\prime}, 2^{\prime}}=3.9$ & $J_{2^{\prime}, 3^{\prime}}=10.2$ & $J_{3^{\prime}, 4}=3.4$ & $J_{5^{\prime}, 4^{\prime}}=1.1$ & \\
\hline & 4.59 & 3.40 & 3.84 & 4.02 & 5.21 \\
\hline \multirow[t]{3}{*}{$7 a$} & d & $\mathrm{dd}$ & $\mathrm{dd}$ & $\mathrm{dd}$ & $\mathrm{d}$ \\
\hline & $J_{1^{\prime}, 2^{\prime}}=7.7$ & $J_{2^{\prime}, 3^{\prime}}=10.0$ & $J_{3^{\prime}, 4^{\prime}}=2.9$ & $J_{5^{\prime}, 4^{\prime}}=1.1$ & \\
\hline & 5.17 & 3.70 & 3.65 & 3.97 & 5.75 \\
\hline \multirow[t]{3}{*}{$7 b$} & d & dd & $\mathrm{dd}$ & dd & $\mathrm{d}$ \\
\hline & $J_{1^{\prime}, 2^{\prime}}=3.6$ & $J_{2^{\prime}, 3^{\prime}}=9.9$ & $J_{3^{\prime}, 4}^{\prime}=3.3$ & $J_{5^{\prime}, 4^{\prime}}=1.0$ & \\
\hline & 5.24 & 3.69 & 3.60 & 4.15 & 4.26 \\
\hline \multirow[t]{3}{*}{ 9a } & d & dd & $\mathrm{dd}$ & $\mathrm{dd}$ & $\mathrm{s}$ \\
\hline & $J_{1^{\prime}, 2^{\prime}}=4.2$ & $J_{2^{\prime}, 3^{\prime}}=10.1$ & $J_{3^{\prime}, 4^{\prime}}=2.9$ & $J_{5^{\prime}, 4^{\prime}}<1$ & \\
\hline & 4.60 & 3.40 & 3.85 & 4.50 & 4.26 \\
\hline \multirow[t]{2}{*}{$9 b$} & $\mathrm{~d}$ & dd & $\mathrm{dd}$ & $\mathrm{dd}$ & $\mathrm{s}$ \\
\hline & $J_{1^{\prime}, 2^{\prime}}=7.3$ & $J_{2^{\prime}, 3^{\prime}}=10.2$ & $J_{3^{\prime}, 4}=2.9$ & $J_{5^{\prime}, 4^{\prime}}=<1$ & \\
\hline
\end{tabular}

Table 3. ${ }^{13} \mathrm{C}$ NMR data of $\mathbf{6 a - 9 a}$ and $6 \mathbf{b}-9 \mathbf{b}\left(\mathrm{D}_{2} \mathrm{O}\right): \delta_{C}[\mathrm{ppm}]$

\begin{tabular}{cccccccc}
\hline Compound & C-1 $^{\prime}$ & C-2 $^{\prime}$ & C-3 $^{\prime}$ & C-4 $^{\prime}$ & C-5 $^{\prime}$ & C-2 & C-5' \\
\hline $\mathbf{6 a}$ & 97.7 & 72.4 & 73.2 & 68.8 & 71.2 & - & 178.8 \\
7a & 97.5 & 72.1 & 73.7 & 69.4 & 73.1 & 160.1 & 149.2 \\
$\mathbf{8 a}$ & 98.9 & 73.3 & 74.5 & 71.2 & 77.0 & 169.0 & 154.5 \\
$\mathbf{9 a}$ & 93.2 & 69.9 & 70.5 & 71.5 & 68.7 & $(a)$ & $(a)$ \\
$\mathbf{6 b}$ & 93.8 & 69.5 & 70.7 & 71.7 & 66.7 & - & 178.8 \\
$\mathbf{7 b}$ & 93.6 & 69.6 & 71.1 & 71.6 & 68.6 & 160.1 & 149.2 \\
$\mathbf{8 b}$ & 94.5 & 69.9 & 70.8 & 71.8 & 72.7 & 169.0 & 154.5 \\
$\mathbf{9 b}$ & 97.2 & 72.1 & 73.1 & 68.5 & 75.6 & $(a)$ & $(a)$ \\
\hline
\end{tabular}

(a) For both structures, quaternary carbons: $\delta_{\mathrm{C}}\left(\mathrm{D}_{2} \mathrm{O}\right)$ : 182.3, 173.6.

Table 4. ${ }^{13} \mathrm{C}$ NMR data of $8 \mathrm{c}$ and $\mathbf{8 d}\left(\mathrm{D}_{2} \mathrm{O}\right): \delta_{C}[\mathrm{ppm}]$

\begin{tabular}{cccccccc}
\hline Compound & C-1 $^{\prime}$ & C-2 $^{\prime}$ & C-3 $^{\prime}$ & C-4 $^{\prime}$ & C-5 $^{\prime}$ & C-2 & C-5' \\
\hline 8c & 103.6 & 84.4 & 77.9 & 85.3 & 72.7 & 169.0 & 154.5 \\
$\mathbf{8 d}$ & 97.1 & 78.4 & 72.4 & 82.8 & 73.2 & 169.0 & 154.5 \\
\hline
\end{tabular}




\section{Experimental Section}

General Procedures. Compounds 1 and $\mathbf{4}$ were synthesized as described in the literature. ${ }^{7}$ Microwave irradiations were performed in a domestic oven at full power $(1500 \mathrm{~W})$ using an air condenser. Melting points were measured in a Thomas Hoover melting point apparatus and are uncorrected. The H NMR spectra were recorded with a Bruker AC200 instrument at $200 \mathrm{MHz}$ and the ${ }^{13} \mathrm{C}$ NMR spectra were recorded at $50 \mathrm{MHz}$ with the same apparatus, using $\mathrm{CDCl}_{3}$ or $\mathrm{D}_{2} \mathrm{O}$, as reported in each case. Chemical shifts are given in $\delta(\mathrm{ppm})$ and coupling constants $(J)$ are in Hz. The 2D-homo and heteronuclear experiments (COSY and HETCOR) were performed with a Bruker AC500 instrument. Acid concentrations are given in \% v/v. Thin layer chromatography (TLC) was performed aluminium sheets coated with silica gel G 60 F254 (Merck, Darmstadt) and UV light and 1:10 v/v $\mathrm{H}_{2} \mathrm{SO}_{4} /$ ethanol/heat were used for detection.

2-Amino-5-[5'-(1',2':3',4'-di-O-isopropylidene- $\beta$-L-arabinopyranosyl)]-1,3,4-thiadiazole (2). 1,2:3,4-Di- $O$-isopropylidene- $\alpha$-D-galacto-1,6-hexadialdo-1,5-pyranose thiosemicarbazone ${ }^{8}$ (261 $\mathrm{mg}, 0.79 \mathrm{mmol})$ was mixed in a mortar with $\mathrm{FeCl}_{3} \cdot 6\left(\mathrm{H}_{2} \mathrm{O}\right)(313 \mathrm{mg}, 1.16 \mathrm{mmol})$ and the mixture was placed in a microwave oven and irradiated for 15 seconds at maximum power. The mixture was dissolved in water $(10 \mathrm{~mL})$ and extracted first with $\mathrm{CH}_{2} \mathrm{Cl}_{2}$, and then with EtOAc. The combined organic layers were dried with $\mathrm{Na}_{2} \mathrm{SO}_{4}$ (anh), concentrated, and purified through a silica gel flash column (cyclohexane-acetone 4:1). Compound 2 was isolated (83 $\mathrm{mg}, 32 \%$ yield): $\mathrm{mp} 262-264{ }^{\circ} \mathrm{C}$, lit. $263-264{ }^{\circ} \mathrm{C} .{ }^{8}$

2-Phenyl-5-[5'-(1',2':3',4'-di-O-isopropylidene- $\beta$-L-arabinopyranosyl)]-1,3,4-oxadiazole (3). To a magnetically stirred solution of compound $5(500 \mathrm{mg}, 1.33 \mathrm{mmol})$ in $10 \mathrm{~mL}$ of $\mathrm{MeOH}$, iodobenzene diacetate (PIDA, $430 \mathrm{mg}, 1.33 \mathrm{mmol})$ and $\mathrm{NaOAc} .3\left(\mathrm{H}_{2} \mathrm{O}\right)(317 \mathrm{mg}, 2.66 \mathrm{mmol})$ were added. The reaction mixture was kept for $24 \mathrm{~h}$ at room temperature and then, even though the reaction was not yet complete, the solution was concentrated and the residue was fractionated using a silica gel flash column, eluted with cyclohexane-acetone 9:1. Compound 3 was obtained (323 mg, $73.5 \%$ yield): $\mathrm{mp} 169^{\circ} \mathrm{C}$, lit. $166-168^{\circ} \mathrm{C} .{ }^{7}$

syn and anti 1,2:3,4-Di- $O$-isopropylidene- $\alpha$-D-galacto-1,6-hexodialdo-1,5-pyranose benzoylhydrazide (5). 1,2:3,4-Di- $O$-isopropylidene- $\alpha$-D-galacto-1,6-hexodialdo-1,5-pyranose $(2.4 \mathrm{~g}, 9.3 \mathrm{mmol})$ was dissolved in the minimal amount of ethanol and $1.29 \mathrm{~g}$ of benzoylhydrazide was added. The mixture was refluxed for 30 minutes, and the reaction was followed by TLC (toluene:EtOAc 3:2). The mixture was concentrated and recrystallized from EtOH: $\mathrm{H}_{2} \mathrm{O}$. The condensed product was obtained (1.37 g, 39\% yield) as a mixture of syn and anti forms, mp: $159-161^{\circ} \mathrm{C}$.

NMR data: $\delta_{\mathrm{H}}\left(\mathrm{CDCl}_{3}\right) 10.87$ (-NH anti), 9.75 (-NH syn), 7.92-7.38 (aromatic protons and $\mathrm{H}-$ 6 syn and anti) $5.70\left(\mathrm{H}-1\right.$ anti, $\left.J_{1,2}=5.1 \mathrm{~Hz}\right), 5.55\left(\mathrm{H}-1\right.$ syn, $\left.J_{1,2}=4.8 \mathrm{~Hz},\right), 4.33(\mathrm{H}-2$ syn and anti, $\left.J_{1,2}=5.0 \mathrm{~Hz}, J_{2,3}=2.4\right), 4.64\left(\mathrm{H}-3\right.$ and H-5, syn and anti), $4.42\left(\mathrm{H}-4\right.$ syn and anti, $J_{3,4}=8.0$ $\mathrm{Hz}, J_{4,5}=2.0$, $), 1.54-1.31\left(-\mathrm{CH}_{3}\right.$ syn and anti). $\delta_{\mathrm{C}}\left(\mathrm{CDCl}_{3}\right) 172.0(\mathrm{C}=\mathrm{O}$, syn and anti), $149.0(\mathrm{C}-$ 
6 syn), 141.7 (C-6 anti), 133.0-127.6 (aromatics, syn and anti), 110.2, 109.6 (quaternary carbons of isopropylidene groups, anti), 109.6, 109.1 (quaternary carbons of isopropylidene groups, syn), 96.1 (C-1 syn), 96.6 (C-1 anti), 70.3 (C-2 syn and anti), 70.7 (C-3 syn), 70.5 (C-3 anti), 68.4 (C4 syn), 66.1 (C-4 anti), 73.4 (C-5 syn), 71.7 (C-5 anti), $24.2-26.1\left(-\mathrm{CH}_{3}\right.$ of isopropylidene groups, syn and anti). Anal. Calcd. for $\mathrm{C}_{19} \mathrm{H}_{26} \mathrm{~N}_{2} \mathrm{O}_{6}: \mathrm{C}, 60.32 ; \mathrm{H}, 6.88 ; \mathrm{N}, 7.41$. Found: C, 60.13; H, 6.93; N, 7.33.

5-[5'-(L-Arabinopyranosyl)]tetrazole (6a and 6b). Thermal procedure: A magnetically stirred solution of compound 1 (114.1 mg, $0.38 \mathrm{mmol})$ in $\mathrm{AcOH}(10 \%, 2.2 \mathrm{~mL})$ was heated at $80{ }^{\circ} \mathrm{C}$. The reaction progress was monitored using TLC (EtOH:EtOAc 4:1) until compound 1 was no longer detected. After $18 \mathrm{~h}$ of heating, the reaction medium was concentrated to dryness and further extracted with $\mathrm{HCCl}_{3}: \mathrm{H}_{2} \mathrm{O}$. Compound $\mathbf{6}$ was obtained from the aqueous phase, $(72 \mathrm{mg}$, $86.2 \%$ yield) as a mixture of $\alpha$ - and $\beta$-pyranose forms.

Microwave procedure: Compound $1(113.1 \mathrm{mg}, 0.38 \mathrm{mmol})$ was dissolved in aqueous acetic acid $(10 \%, 10 \mathrm{~mL})$ and the mixture was irradiated $(3 \times 40 \mathrm{sec})$. After that, AcOH solution was added $(10 \mathrm{~mL})$ and the solution was irradiated $(2 \times 40 \mathrm{sec}, 1 \times 20 \mathrm{sec})$. TLC showed the presence of starting material. Consequently, the mixture was concentrated to dryness and further extracted with $\mathrm{CHCl}_{3}$. The remaining insoluble material was compound 6 (68.6 mg, 75\% yield), while the soluble product was identified as compound 1. To the remaining compound 1, aqueous $\mathrm{AcOH}$ $(10 \%, 10 \mathrm{~mL})$ was added and the mixture was irradiated $(2 \times 40 \mathrm{sec}, 1 \times 30 \mathrm{sec})$ and, after that, compound 1 was no longer detected. Compound $\mathbf{6}$ was obtained as a syrup by evaporation of the reaction medium (11.5 $\mathrm{mg}, 89.4 \%$ yield).

Anal. Calcd. for $\mathrm{C}_{6} \mathrm{H}_{10} \mathrm{~N}_{4} \mathrm{O}_{5}$ : C, 33.03; H, 4.59; N, 25.69. Found: C, 32.89; H, 4.64; N, 25.71 .

2-Amino-5-[5'-(L-arabinopyranosyl)]-1,3,4-thiadiazole (7a and 7b). Thermal procedure: Compound 2 (40.9 mg, $0.12 \mathrm{mmol})$ was dissolved in the minimal amount of acetone and then aqueous $\mathrm{H}_{2} \mathrm{SO}_{4}(8 \%, 1 \mathrm{~mL})$ was added. The mixture was allowed to stand at room temperature for $18 \mathrm{~h}$ and no reaction was observed. When the mixture was heated at $60{ }^{\circ} \mathrm{C}$, the starting material decomposed.

Microwave procedure: To a solution of compound $2(21.3 \mathrm{mg}, 0.06 \mathrm{mmol})$ in $\mathrm{MeCN}(0.6$ $\mathrm{mL})$, aqueous $\mathrm{H}_{2} \mathrm{SO}_{4}(1 \%, 5.3 \mathrm{~mL})$ was added. The mixture was irradiated $(2 \mathrm{x} 20 \mathrm{sec})$, then neutralized with $\mathrm{BaCO}_{3}$, filtered and concentrated. The title compound was obtained (12.5 mg, $42 \%$ yield) as a mixture of $\alpha$ and $\beta$ pyranose forms.

Anal. Calcd. for $\mathrm{C}_{7} \mathrm{H}_{11} \mathrm{~N}_{3} \mathrm{O}_{5} \mathrm{~S}: \mathrm{C}, 33.73 ; \mathrm{H}, 4.42 ; \mathrm{N}, 16.87$. Found: C, 33.89; H, 4.61; N, 16.98 . 2-Phenyl-5-[5'-(L-arabinopyranosyl)]-1,3,4-oxadiazole (8a and 8b) and 2-phenyl-5-[5'-(Larabinofuranosyl)]-1,3,4-oxadiazole (8c and 8d). Thermal procedure: A magnetically stirred solution of compound $3(110.3 \mathrm{mg}, 0.30 \mathrm{mmol})$ in aqueous $\mathrm{AcOH}(10 \%, 1.7 \mathrm{~mL})$ was heated for $6 \mathrm{~h}$ at $80{ }^{\circ} \mathrm{C}$ and, since no change was observed, the same mass of 3 was dissolved in the minimal amount of acetone and aqueous $\mathrm{H}_{2} \mathrm{SO}_{4}(8 \%, 1 \mathrm{~mL})$ was added. The mixture was kept at room temperature for $1 \mathrm{~h}$ and, since no reaction was observed, it was heated for $1 \mathrm{~h}$ at $60{ }^{\circ} \mathrm{C}$ and analyzed by TLC. As no starting material remained, the reaction medium was neutralized using 
$\mathrm{BaCO}_{3}$ and filtered. The filtrate was concentrated to dryness to give compound $\mathbf{8}$ as a syrup (83.4 mg, 93.3\% yield).

Microwave procedure: A mixture of compound $3(110.2 \mathrm{mg}, 0.30 \mathrm{mmol})$ and aqueous $\mathrm{AcOH}$ $(10 \%, 20 \mathrm{~mL})$ was irradiated $(7 \times 20 \mathrm{sec})$ and no changes were observed. After that, compound $3(5.5 \mathrm{mg}, 0,015 \mathrm{mmol})$ was treated with aqueous $\mathrm{H}_{2} \mathrm{SO}_{4}(1 \%, 1.3 \mathrm{~mL})$, and irradiated $(6 \times 10$ sec). No reaction was observed. Therefore, $\mathrm{MeCN}$ was added dropwise until complete dissolution of 3, and this solution was irradiated for $80 \mathrm{sec}$. The mixture was neutralized with $\mathrm{BaCO}_{3}$ and filtered. The filtrate was concentrated to dryness and compound $\mathbf{8}$ was obtained (4.2 mg, 97\% yield).

NMR data: $\delta_{\mathrm{H}}\left(\mathrm{D}_{2} \mathrm{O}\right)$ 8.0-7.3 (aromatics). $\delta_{\mathrm{C}}\left(\mathrm{D}_{2} \mathrm{O}\right)$ 133.7-128.6 (aromatics). Anal. Calcd. for $\mathrm{C}_{13} \mathrm{H}_{14} \mathrm{~N}_{2} \mathrm{O}_{6}$ : C, 53.06; H, 4.76; N, 9.52. Found: C, 53.11; H, 4.81; N, 9.80.

$\boldsymbol{N}$-Acetyl-D-galacturonopyranosyl hydrazide (9a and 9b). Thermal procedure: Compound 3 (188.1 mg, $0.6 \mathrm{mmol})$ was treated with aqueous $\mathrm{H}_{2} \mathrm{SO}_{4}(8 \%, 3.3 \mathrm{~mL})$ and heated at $60{ }^{\circ} \mathrm{C}$ with continuous stirring. The reaction progress was monitored by TLC (EtOH:EtOAc 4:1) until compound 1 was no longer detected. After $18 \mathrm{~h}$ of heating the reaction medium was concentrated to dryness and extracted with $\mathrm{CHCl}_{3}: \mathrm{H}_{2} \mathrm{O}$. From the aqueous phase compound 9 was obtained (77 mg, 55.5\% yield) as a mixture of $\alpha$ - and $\beta$-pyranose forms.

Microwave procedure: To a solution of compound $3(28.1 \mathrm{mg}, 0.09 \mathrm{mmol})$ in $\mathrm{MeCN}(0.5$ $\mathrm{mL})$, aqueous $\mathrm{H}_{2} \mathrm{SO}_{4}(1 \%, 8 \mathrm{~mL})$ was added. The mixture was irradiated ( 4 x $\left.20 \mathrm{sec}\right)$, and the reaction was followed by TLC (EtOH:EtOAc 7:3). The reaction medium was neutralized with $\mathrm{BaCO}_{3}$, filtered and concentrated to dryness to give compound $9(15.0 \mathrm{mg}, 72.0 \%$ yield $)$.

NMR data: $\delta_{\mathrm{H}}\left(\mathrm{D}_{2} \mathrm{O}\right) 1.87\left(-\mathrm{CH}_{3}\right) . \delta_{\mathrm{C}}\left(\mathrm{D}_{2} \mathrm{O}\right) 24.1\left(-\mathrm{CH}_{3}\right)$. Anal. Calcd. for $\mathrm{C}_{6} \mathrm{H}_{10} \mathrm{~N}_{4} \mathrm{O}_{5}: \mathrm{C}, 33.03$; H, 4.59; N, 25.69. Found: C, 32.90; H, 4.71; N, 25.79.

\section{Acknowledgments}

Thanks are given to the UBA for financial support (project number X082). Dr. N. B. D'Accorso is a research member of CONICET.

\section{References}

1. Zhang, H. Y.; Yu, H. W.; Ma, L. T.; Min, J. M.; Zhang, L. H. Tetrahedron: Asymmetry 1998, 9, 141.

2. Yu, H. W.; Zhang, H. Y.; Yang, Z. J.; Min, J. M.; Ma, L. T.; Zhang, L. H. Pure Appl. Chem. 1998, 70, 435.

3. Yang, Z. J.; Yu, H. W.; Min, J. M.; Ma, L. T.; Zhang, L. H. Tetrahedron: Asymmetry 1997, 8, 2739. 
4. Huryn, D. M.; Sluboski, B. C.; Tam, S. Y.; Todaro, L. J.; Weigele, M. Tetrahedron Lett. 1989, $30,6259$.

5. Suhadonik, R. J. Prog. Nucleic Acid Res. Mol. Biol. 1979, 22, 193.

6. Jayaram, H. N.; Dion, R. L.; Glazer, R. I.; Johns, D. G.; Robins, R. K.; Srivastava, P. C.; Cooney, D. A. Biochem. Pharmacol .1982, 31, 2371.

7. Martins Alho, M. A.; D’Accorso, N. B. J. Heterocyclic Chem. 1999, 36, 177.

8. Martins Alho, M. A.; D’Accorso, N. B. J. Heterocyclic Chem. 2000, 37, 811.

9. Söderberg, E.; Westman, J.; Stefan, O. J. Carbohydrate Chem. 2001, 20, 397.

10. Sainsbury, M.; Fairbairn, R. E. Rodd's Chemistry of Carbon Compounds, $2^{\text {nd }}$ Edn.; IV Heterocyclic Compounds - Part D, Elsevier Science Publishers B. V.: The Netherlands, 1986; p 89.

11. Cannizzaro, C. E.; Thiel, I. M. E.; D'Accorso, N. B. J. Heterocyclic Chem. 1998, 35, 481.

12. Acree, T. E.; Shallenberger, R. S. Mattick, L. R. Carbohydr. Res. 1968, 6, 498.

13. Wertz, P. W.; Garver, J. C. Anderson, L. J. Am. Chem. Soc. 1981, 103, 3916.

14. Bock K.; Pedersen, C. Adv. Carbohydrate Chem. Biochem. 1984, 41, 27. 